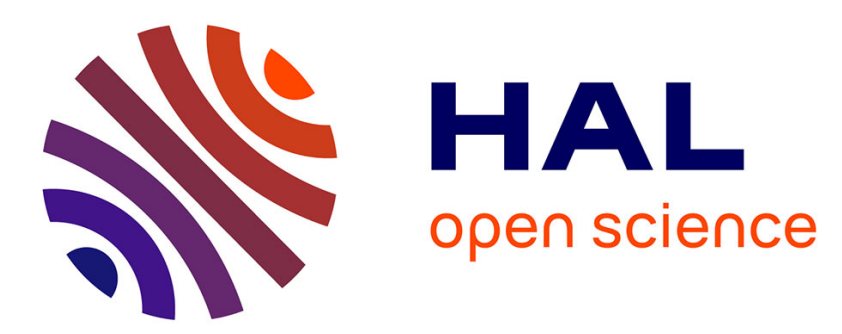

\title{
A novel system coupling an electro-Fenton process and an advanced biological process to remove a pharmaceutical compound, metronidazole
}

A. Aboudalle, Hayet Djelal, L. Domergue, Florence Fourcade, Abdeltif Amrane

\section{To cite this version:}

A. Aboudalle, Hayet Djelal, L. Domergue, Florence Fourcade, Abdeltif Amrane. A novel system coupling an electro-Fenton process and an advanced biological process to remove a pharmaceutical compound, metronidazole. Journal of Hazardous Materials, 2021, 415, pp.125705. 10.1016/j.jhazmat.2021.125705 . hal-03225455

\section{HAL Id: hal-03225455 \\ https://hal.science/hal-03225455}

Submitted on 10 Jun 2021

HAL is a multi-disciplinary open access archive for the deposit and dissemination of scientific research documents, whether they are published or not. The documents may come from teaching and research institutions in France or abroad, or from public or private research centers.
L'archive ouverte pluridisciplinaire HAL, est destinée au dépôt et à la diffusion de documents scientifiques de niveau recherche, publiés ou non, émanant des établissements d'enseignement et de recherche français ou étrangers, des laboratoires publics ou privés. 


\title{
A novel system coupling an electro-Fenton process and an advanced biological process to remove a pharmaceutical compound, metronidazole
}

Arwa Aboudalle $^{\mathrm{a}}$, Hayet Djelal ${ }^{\mathrm{b},{ }^{*}}$, Lionel Domergue $^{\mathrm{c}}$, Florence Fourcade ${ }^{\mathrm{a}}$, Abdeltif Amrane $^{\mathrm{a}}$

${ }^{a}$ Ecole Nationale Supérieure de Chimie de Rennes, Université de Rennes 1, UMR-CNRS 6226,11 Allée de Beaulieu, CS 50837, 35708 Rennes cedex 7, France.

${ }^{\text {b} U n i l a s a l l e-E c o l e ~ d e s ~ M e ́ t i e r s ~ d e ~ l ' E n v i r o n n e m e n t, ~ C a m p u s ~ d e ~ K e r ~ L a n n, ~} 35170$ Bruz, France.

${ }^{\mathrm{c}}$ Normandie Univ, ENSICAEN, UNICAEN, CNRS, Laboratoire Catalyse et Spectrochimie, 14000 Caen, France.

*Corresponding author: Unilasalle-Ecole des Métiers de l'Environnement, Campus de Ker Lann, 35170 Bruz,

E-mail addresses: hayet.djelal@unilasalle.fr (H. Djelal)

\begin{abstract}
The objective of this study was to improve the mineralization of metronidazole, a recalcitrant antibiotic by the development of a new combined process coupling electro-Fenton and a biological process. For biotreatment, various strategies were considered bioaugmentation, bioacclimatation and biostimulation alone or combined. So, the novelty of this strategy is to combine advanced oxidation process with advanced biological process. The conventional biotreatment with activated sludge after $120 \mathrm{~h}$ of culture, led to $58.1 \%$ mineralization; whereas the pure isolated strains, from activated sludge culture in the presence of metronidazole by-products, identified as Pseudomonas putida (strain A) and Achromobacter $s p$ (strain B), led to 37.2 and $40.1 \%$ respectively. After original acclimation of the isolated strains to electrolysis by-products, the mineralization levels reached $75.6 \%$ and $72.9 \%$ for strains A and B respectively after $120 \mathrm{~h}$ of culture. The results showed that the mineralization of metronidazole by-products was the most important in the case of the combination of autochthonous bioaugmentation and biostimulation, with $96.1 \%$ after $120 \mathrm{~h}$ of treatment. By coupling the two processes, the global treatment reached therefore a mineralization yield of $97 \%$ with a reduction in processing time of 16 days compared to previous conventional biological treatment.
\end{abstract}


Keywords : Metronidazole; electro-Fenton process; bioaugmentation; biostimulation; activated sludge

\section{Introduction}

It has been proved by previous studies, that different antibiotics are detected in wastewater and surface water [1-3]. Biological treatment is not capable by its own to eliminate those antibiotics completely; they are consequently transferred to the receiving water systems. The most harmful significant effect of antibiotics on the environment is their impact on aquatic organisms, leading to an unbalanced ecological system [4-6]. Furthermore, antibiotic resistance phenomenon is another important negative effect. Advanced oxidation processes (AOPs) are often considered for the removal of recalcitrant compounds, such as antibiotics; for instance, among the main processes applied, photocatalysis, which can be based on novel catalysts, for example silicate glass matrix (3-DG) coupled with $\mathrm{Cu}_{2} \mathrm{O} / \mathrm{Cu}_{2} \mathrm{~V}_{2} \mathrm{O}_{7}$ for the degradation of sulfametoxazole [7] or $\mathrm{g}_{-} \mathrm{C}_{3} \mathrm{~N}_{4} / \mathrm{MoS}_{2}$-PANI nanocomposite for the degradation of bisphenol-A [8]. Among advanced oxidation processes, electrochemical ones (EAOPs) appear highly promising, illustrated by the increase of scientific publications related to this class of processes [9], as it is the case for the change electro-Fenton process, which is also largely applied for the degradation of antibiotics [10-12]. Olvera-Vargas applied this process on real pharmaceutical wastewater paired with a BDD anode and showed an improvement of the biodegradability of refractory wastewater [13]. Several current studies are based on the development of novel materials specifically bio-inspired and biomaterials [14].

Biological conventional treatment of recalcitrant compounds is well known for its inefficiency. However, strategies are carried by some authors to improve the bioremediation yield with activated sludge or specific strains. This is possible by the development of biostimulation, bioacclimation and bioaugmentation processes alone or combined. Biostimulation allows to enhance the activity of activated sludge or autochthonous strains. Semrany et al, explained that enhancement of microbial growth can be achieved by addition of a carbon source and/or by addition of mediator, cofactor or inductor to stimulate enzyme production [15]. Djelal et al, reached the bioremediation of doxycycline, an antibiotic by $90 \%$ with biostimualtion of activated sludge by addition of copper, i.e. an increase of $30 \%$ compared to the witness (activated sludge alone) [16]. Autochthonous bioaugmentation was applied for the biodegradation of biorecalcitrant compounds such as biphenyl [17]. 
Metronidazole (MTZ) is one of the highly resistant pharmaceutical drugs detected in treated sewage water [18], it is characterized by its antibacterial and anti-inflammatory nature. MTZ is a non-biodegradable antibiotic, soluble in water [19], able to roam freely though wastewater plants, skipping the multiple water treatment processes, leading to expose the aquatic ecosystem to danger. Thus, it is mandatory to treat MTZ prior to its discharge into biological treatment process and receiving wastewater plants.

Combining chemical and biological treatments serves together to eliminate contaminants from water [20-22]. This combination is applied in order to overcome the limits of individual remediation techniques, and to get a better efficiency in eliminating antibiotics. In fact, carrying a chemical pre-treatment serves to turn the persistent organic compounds into more biodegradable intermediates, which are then subjected to a less expensive biological treatment [23]. An electro-Fenton pretreatment can oxidize the recalcitrant compounds by in situ formation of hydroxyl radicals by the electro-generated Fenton $\left(\mathrm{H}_{2} \mathrm{O}_{2}, \mathrm{Fe}^{2+}\right)$ reagents. A variety of researches proved the pertinence of combining an electro-Fenton with a biological treatment [11-12, 24-25].

Nevertheless, conventional biological treatment may encounter limitations via the possible production of refractory molecules during the electro-Fenton process and by the time of treatment which can appear too long for an efficient treatment. For example, Ferrag-Siagh et al. applied such combined process to the treatment of an antibiotic, tylosin [11]. The mineralization of the biodegradable part of the by-products by activated sludge from tylosin was fast and reached $56 \%$ after 2 days of cultivation; while the mineralization rate decreased then significantly, reaching only $67 \%$ after 20 days of treatment. This showed the presence of refractory by-products in the culture medium and consequently microorganisms need a phase of adaptation to degrade these products. To overcome such difficulty, it is proposed in this study to replace conventional biological treatment by an advanced biological treatment, and hence the coupling of an advanced oxidation process "electro-Fenton" with an advanced biological process "biostimulation and/or bioaugmentation" is targeted.

More precisely, biostimulation consists in the improvement of biodegradation by the addition of nutrients or electron acceptors. The low microbial growth can negatively influence the biodegradability [26]; the addition of substrates can help to improve the growth of microbial populations and hence can be helpful for the removal of contaminants [15]. Bioaugmentation consists to enhance the biodegradation process by adding specific microorganisms to the 
indigenous microbial community present in the solution to be treated [27]. In fact, three types of microorganisms can be used [15,28]. The first type involves microorganisms isolated from the contaminated media. These microorganisms are acclimated to the pollutant and then reinjected in the same medium. This type of bioaugmentation belongs to the autochthonous one. The second type of bioaugmentation involves the inoculation into the contaminated medium of exogenous microorganisms isolated from another medium, it is called allochthonous bioaugmentation. The third type concerns the gene bioaugmentation that consists in the formation of genetically modified microorganisms and applying them in the contaminated medium. However, to improve the removal of the pollutant, various studies have considered the coupling of bioaugmentation and biostimulation process. For example, Raimondo et al. has observed the highest elimination rate of lindane, an organochlorine pesticide, by the coupling of bioaugmentation and biostimulation [29].

In previous study, we carried out an electro-Fenton process coupling with a conventional biological treatment using activated sludge in order to mineralize metronidazole. The results showed a mineralization of $84.6 \%$ of the electrolysis by-products in $504 \mathrm{~h}$ [30]. Biological conventional treatment has various disadvantages in terms of processing time and hard COD formation. The objective of this study is to improve the efficiency of the mineralization by using advanced biological treatment. In this sense, biostimulation, bioacclimation and autochthonous bioaugmentation were carried out. Monitoring the mineralization was assessed during biological treatments and the detection of the electrolysis by-products during electrochemical and biological treatment was evaluated.

\section{Materials and methods}

\subsection{Chemicals and materials}

MTZ (2-methyl-5-nitroimidazole-1-ethanol) was purchased from Sigma-Aldrich (Saint Quentin Fallavier, France). $\mathrm{FeSO}_{4} \cdot 7 \mathrm{H}_{2} \mathrm{O}$ (purity $99 \%$ ) served as a catalyst source and $\mathrm{Na}_{2} \mathrm{SO}_{4}$ (purity $99 \%$ ) was employed as an inert supporting electrolyte. Both solutions were obtained from Acros Organics (Thermo Fisher Scientific, Geel, Belgium). Sigma-aldrich and Acros Organics provided all the needed chemicals for analysis. Ultrapure water (Millipore Elga) was used to prepare all solutions. 


\subsection{Electrochemical Apparatus and Procedures}

An electrochemical mono-compartment batch reactor containing $250 \mathrm{~mL}$ of solution was used at ambient temperature $\left(20^{\circ} \mathrm{C}\right)$. An ammeter power supply (Microsonic systems, Microlab MX 20V-2A, France) was employed to apply a current intensity of $100 \mathrm{~mA}$. A threedimensional graphite felt electrode of $42 \mathrm{~cm}^{3}$ (Le Carbone Lorraine RVG 4000 Mersen, Paris la Défense, France) was used as cathode, located on the inner wall of the cell. A cylindrical platinum anode $\left(31.2 \mathrm{~cm}^{2}\right)$ was located at the center of the electrochemical reactor and surrounded by the cathode to get a good potential distribution. 10 min prior to the electrolysis and throughout the experiments, compressed air was bubbled into the solution in order to reach a stationary $\mathrm{O}_{2}$ concentration. The solution to be treated was adjusted to $\mathrm{pH} 3$ and contained metronidazole as pollutant, $\mathrm{FeSO}_{4} \cdot 7 \mathrm{H}_{2} \mathrm{O}$ and $\mathrm{Na}_{2} \mathrm{SO}_{4}$ as supporting electrolyte at concentrations of $100 \mathrm{mg} . \mathrm{L}^{-1}, 0.1 \mathrm{mmol} . \mathrm{L}^{-1}$ and $50 \mathrm{mmol} . \mathrm{L}^{-1}$, respectively.

\subsection{Isolation and identification of strains}

Strains were isolated from the activated sludge as follows: during 504 hours of culture of activated sludge in the presence of MTZ by-products from electro-Fenton process as sole carbon sources at $25^{\circ} \mathrm{C}$ and $200 \mathrm{rpm}$, the isolation was carried out by serial dilutions in physiological water. The samples $(100 \mu 1)$ were placed in a Luria-Bertani agar (LB) medium on Petri dish (10 g. $\mathrm{L}^{-1}$ of tryptone, 5 g. $\mathrm{L}^{-1}$ of sodium chloride, $5 \mathrm{~g} . \mathrm{L}^{-1}$ of yeast extract supplemented by glucose $\left(1\right.$ g. $\left.\mathrm{L}^{-1}\right)$.

The identification of the isolated strains was performed by Matrix-Assisted Laser Desorption Ionization-Time of Flight Mass Spectrometry (MALDI-TOF) (Labocea, Fougère, France).

\subsection{Preparation of isolated strains inocula}

Before inoculation, the isolated strains were grown at $28^{\circ} \mathrm{C}$ and $150 \mathrm{rpm}$ in $\mathrm{LB}$ medium supplemented by 1 g. $\mathrm{L}^{-1}$ of glucose until growth reached the beginning of the stationary phase. At the end of incubation, cells were pelleted aseptically by centrifugation (4000 rpm, $15 \mathrm{~min}$ ), washed twice with sterile physiological water and concentrated in $35 \mathrm{ml}$ of physiological water. The suspension obtained was then used for inoculation. For all experiments the volume of inoculation was $4 \%(\mathrm{v} / \mathrm{v})$ corresponding to about $0.25 \mathrm{~g} . \mathrm{L}^{-1}$ for the two strains. 


\subsection{Acclimation of the isolated strains}

The isolated strains were acclimated to the biorefractory part of the electrolysis by-products, namely those remaining after 48 hours of biological treatment of pure strains. A sterile solid medium was considered for acclimation; in addition to electrolysis by-products, it contained the following minerals (mg.L $\mathrm{L}^{-1}$ ): $\mathrm{K}_{2} \mathrm{HPO}_{4}$ (208); $\mathrm{KH}_{2} \mathrm{PO}_{4}$ (85); $\mathrm{Na}_{2} \mathrm{HPO}_{4}, 2 \mathrm{H}_{2} \mathrm{O}$ (154.4); $\mathrm{MgSO}_{4}, 7 \mathrm{H}_{2} \mathrm{O}$ (22.6); $\mathrm{CaCl}_{2}$ (27.6); $\mathrm{FeCl}_{3}, 6 \mathrm{H}_{2} \mathrm{O}(0.26) ; \mathrm{NH}_{4} \mathrm{Cl}$ (75); as well as agar-agar, the $\mathrm{pH}$ was adjusted to 7 . Acclimation consisted in the following steps (Fig.1):

- Acclimation of each pure strain on $20 \%$ of the by-products as sole carbon source and $80 \%$ of ultrapure water.

- After incubation at $28^{\circ} \mathrm{C}$ for $72 \mathrm{~h}$, the appeared colonies were afterwards seeded in a solid medium containing $50 \%$ of the electrolysis by-products and $50 \%$ of ultra-pure water.

- The by-product percentage was increased up to $80 \%$ and then finally up to $100 \%$. Strains growing on the solid medium composed of $100 \%$ electrolysis by-products were used in the experiments.

\subsection{Preparation of the activated sludge}

Obtaining the inoculated activated sludge was ensured from a local wastewater treatment plant (Rennes Beaurade, France). The activated sludge was kept active in an $8 \mathrm{~L}$ bioreactor at room temperature by adding nutrients $\left(\mathrm{g} . \mathrm{L}^{-1}\right)$ : peptone, $0.64 ; \mathrm{K}_{2} \mathrm{HPO}_{4}, 0.11 ; \mathrm{NH}_{4} \mathrm{Cl}, 15.2$; $\mathrm{CH}_{3} \mathrm{COONa}, 140$ and an additional source of carbon (viandox). The activated sludge was washed three times with tap water and two times by ultra-pure water. Before each washing the sludge was centrifuged at $4000 \mathrm{rpm}$ for $10 \mathrm{~min}$ (Jouan centrifuge, Thermo Fisher Scientifics, Saint Herblain, France). Carbon residues and mineral nutrients present in the activated sludge were removed before their use in the experiments.

\subsection{Determination of the biological oxygen demand $\left(\mathrm{BOD}_{5}\right)$}

In order to assess the biodegradability of the MTZ molecule, electrolysis by-products and biological by-products, the $\mathrm{BOD}_{5}$ measurements were released in Oxitop IS6 (from WTW, Alès, France) at $20^{\circ} \mathrm{C}, \mathrm{pH} 7$ and in obscurity during 5 days. The details of the protocol were presented in a previous study [30]. 


\subsection{Biological treatment}

For all biological experiments, the cultures were realized in duplicate for 120 hours in $250 \mathrm{~mL}$ Erlenmeyer flasks closed with a cellulose cap allowing the oxygenation. The flask contains $100 \mathrm{~mL}$ of electrolyzed metronidazole solutions at $28^{\circ} \mathrm{C}$ with a stirring of $150 \mathrm{rpm}$. The $\mathrm{pH}$ was adjusted to 7.0. The conditions of the different biological treatments are presented in Table 1.

\subsection{Analytical procedures}

\subsubsection{Dissolved organic carbon (DOC) measurements}

DOC was obtained using a Schimadzu TOC-VCPH / CPG Total Organic Analyzer. The analysis is based on the combustion of dissolved organic material at $680{ }^{\circ} \mathrm{C}$ to form $\mathrm{CO}_{2}$ which is detected by a non-dispersive Infra-Red Detector (NDIR). The values of DOC allowed to determine the \% of mineralization as indicated in Eq. 1:

Mineralization $(\%)=\left(\mathrm{DOC}_{0}-\mathrm{DOC}\right) / \mathrm{DOC}_{0} \times 100 \%$

Where $\mathrm{DOC}_{0}$ and DOC correspond to the value before and after treatment, respectively.

\subsubsection{Chemical Oxygen Demand (COD) measurements}

Nanocolor® CSB 160 kits from Macherey-Nagel (Düren, Germany) was used to evaluate the COD value of MTZ and its degradation by-products. The oxidation of the latter was realized at $160^{\circ} \mathrm{C}$ for 30 minutes with potassium dichromate $\left(\mathrm{K}_{2} \mathrm{Cr}_{2} \mathrm{O}_{7}\right)$ in a strong acid medium $\left(\mathrm{H}_{2} \mathrm{SO}_{4}\right)$. The measurements were carried out using the Nanocolor photometer at $436 \mathrm{~nm}$.

\subsubsection{LC-MS/MS method}

Liquid chromatography-mass spectrometry (UPLC-MS / MS) was used to identify the byproducts of MTZ during electrolysis and biological treatment. Waters Acquity UPLC system (Waters, Manchester, UK) was used for the separation of the analytes. UPLC column was C$18-(2.1 \mathrm{~mm} \times 100 \mathrm{~mm} ; 1.7 \mu \mathrm{m})$ (Milford, MA, USA). The elution was conducted with elution gradient of phase A/phase $\mathrm{B}$ at the flow rate of $0.4 \mathrm{~mL} \cdot \mathrm{min}^{-1}$. The phase A was performed in ultra-pure water with $0.1 \%$ formic acid and the phase B in acetonitrile with $0.1 \%$ formic acid. Waters Micromass Quattro Premier (Waters Corporation,-Manchester, UK) triple quadrupole 
mass spectrometer was used to detect-the separated compounds. More details of the analytical detection were presented in our previous study [30].

\section{Results and discussion}

\subsection{MTZ Mineralization by electro-Fenton pretreatment coupled to biological treatment}

The main objective of this study was to mineralize metronidazole. Our previous study showed a total absence of biodegradability of Metronidazole [30]. This proves that a direct biological treatment would not be efficient and hence the need for a pretreatment. In this sense, the electro-Fenton process was used as a pretreatment. After 20 min of electrolysis, a total degradation of MTZ was reached, while after 1 hour of electrolysis, the mineralization yield reached only $16.1 \%$, showing the formation of MTZ by-products [30]. These latter were characterized by a biodegradability of 0.46 (Fig.2), namely above the limit of biodegradability, 0.4 [31], showing the feasibility of a subsequent biological treatment.

A biological treatment with activated sludge was carried out in the preliminary study showing a mineralization yield of $84.6 \%$ after $504 \mathrm{~h}$ of treatment [30]. During the course of the experiment, regular sampling of the culture broth was performed to follow the microbial diversity of the broth through inoculation of Petri dishes containing LB agar medium supplemented by glucose. In addition to a decrease of the number of cells, a decrease of the microbial diversity should be highlighted, which was especially noticeable at the end of culture (504 h), since only two different strains remained in the Petri dishes (Fig. 3).

A Matrix-Assisted Laser Desorption Ionization-Time of Flight Mass Spectrometry allowed the identification of the two strains that belonged to two different bacterial genera, namely Pseudomonas putida (strain A) with a certainty of $99 \%$ for the first one and Achromobacter $s p$ (strain B) for the second one. For the latter strain, it was not possible to discriminate between two species, denitrificans $50 \%$ and xylosoxidanx $50 \%$. The Pseudomonas putida strain is widely used for the biodegradation of recalcitrant aromatic compounds, since the bacteria cells undergo fundamentals changes in cellular physiology when the microorganism is subjected to environment perturbation [32]. Probably the stress caused by the presence of biorecalcitrant by-products induced specific sets of proteins and these proteins are designed for the elimination of stress agents [32]. In the same way, P. putida was used as a bio- 
enhancing agent in various studies [33-35]. Regarding the second identified strain, Achromobacter $s p$ have also been implemented for the degradation of recalcitrant pollutants [36-39]. It is also considered among the most widely strains used in bioaugmentation [40].

The two isolated strains were then considered to perform biological treatment of the electrolyzed solution, in pure cultures or in combination and compared with the activated sludge. Activated sludge and pure strain culture on the electrolyzed by-products as the sole carbon source was therefore performed and the corresponding results are displayed in Fig.4.

As shown, for activated sludge, about $40 \%$ decrease of the DOC value was observed after 24 $\mathrm{h}$ of culture. The decrease was then less pronounced $55 \%$ mineralization yield was obtained after $48 \mathrm{~h}$ and continued at low rate until the end of the culture (58.1\% after $120 \mathrm{~h}$ ). For pure strains, about $40 \%$ decrease of the DOC values can also be noticed after only $24 \mathrm{~h}$. Then and contrarily to the use of activated sludge, no significant decrease in the DOC values was then observed $(37.2 \%, 40.1 \%, 42.61 \%$ after $120 \mathrm{~h}$ for Strain A, B and co-culture respectively).

These results showed that the use of pure strains alone or in co-culture to treat electrolysis byproducts was less effective than the use of activated sludge. Indeed, the use of pure strains or their co-culture lead to neglect other microorganisms, which can be effective in the treatment of electrolysis by-products, but which has a low coefficient of growth; this fact makes their isolation difficult. Activated sludge contains a wide variety of microorganisms that can be involved in the assimilation of organic compounds, through for instance their enzyme pool and possible synergistic effects between microorganisms, even if they are not major species of the microbial flora of the sludge [41]. From this, the lower efficiency of the pure strains or their co-culture was not unexpected. These results are in agreement with some other reports. Indeed, Buitrón et al. have shown that the use of a consortium consisting of activated sludge to degrade phenolic compounds was more effective than strains isolated from activated sludge in pure form or consortium [41]. In the study of Chebli et al, activated sludge culture on byproducts from an irradiated dyes solution by photocatalysis was also more relevant than the culture of a pure strain Pseudomonas fluorescens strain [42].

\subsection{Effect of acclimation}

The mineralization yield of pollutants can be influenced by the acclimation of microorganisms [43]. It should be observed that the biodegradability of by-products decreased after biological treatment to reach 0.32 (Fig.2); while it was 0.46 at the end of the electro- 
Fenton pretreatement [30]. This indicated, as expected, the consumption of the most readily compounds during the biological treatment and account for the decrease (for activated sludge) or the cessation (for the isolated strains) of the mineralization observed after few days of culture. For pure strains, after 48 hours of culture, the remaining part of the by-product is considered to be a hard COD. In order to improve the mineralization, acclimation of the two isolated strains to the by-products remaining after $48 \mathrm{~h}$ of biological treatment by the pure strains were carried out. Fig.5 shows the effect of acclimation on the mineralization of electrolysis by-products. A clear improvement was observed since the DOC decrease reached $75.6 \%$ and $72.9 \%$ for the strains A and B after $120 \mathrm{~h}$, respectively. Indeed, the successive exposure of bacteria to pollutants led to a change in bacterial metabolism. Recent studies showed that bacterial cells displays different properties depending on long-term exposure of bacteria to organic compounds in comparison to the absence of exposure [44]. In new environmental conditions, bacterial cells develop a chemical tolerance to the surrounding environment, and adapt their metabolism to degrade pollutants. The adaptation can lead to a genetic mutation or induction or depression of a specific enzyme [45]. Various studies showed a positive role of the acclimation of Pseudomonas sp and Achromobacter $s p$ on the degradation of refractory pollutants $[46,47]$.

\subsection{Effect of co-culture}

In order to determine the influence of the co-culture on the mineralization of the electrolysis by-products, different co-cultures were carried out with the two acclimated strains A and B as follows: The size of the inocula for the co-culture $\mathrm{AB}(50 \% / 50 \%)$ was $2 \% / 2 \% \mathrm{v} / \mathrm{v}, 3.2$ $\% / 0.8 \% \mathrm{v} / \mathrm{v}$ for the co-culture $\mathrm{AB}(80 \% / 20 \%)$ and $0.8 \% / 3.2 \% \mathrm{v} / \mathrm{v}$ for the co-culture AB $(20 \% / 80 \%)$. The total volume of inocula was $4 \%$ for all experiments. It can be observed that there were no significant differences regarding the mineralization yields obtained for the 3 ratios tested (Fig.6); after $120 \mathrm{~h}$ they were $65.9 \%, 56.6 \%$, and $64.9 \%$, for the ratio $50 \% / 50 \%, 80 \% / 20 \%$ and $20 \% / 80 \%$ respectively. These mineralization yields were below those recorded during pure cultures of each strain (Fig.5). Two hypotheses can be proposed to account for this behavior: The first is that the interaction of the two strains had a negative effect on the bacterial capacity for mineralization; the second is the absence of complementary between the two strains, the absence of synergistic effects. The ratio $50 \% / 50 \%$ was considered thereafter since it led to a slightly higher mineralization compared to the other co-cultures. Another approach based on advanced biological treatment was consequently considered to improve the mineralization of by-products. 


\subsection{Effect of bioaugmentation}

In order to improve the mineralization of MTZ by-products, advanced biological processes were carried out. The first technique of this process was to apply the autochthonous bioaugmentation of the activated sludge (AS) using the isolated pure strains A and B and the co-culture of both. This technique could be useful for a better removal of MTZ by-products by increasing the concentration of specific strains present in the activated sludge. Bioaugmentation experiments of activated sludge were carried out with acclimated and nonacclimated A and B strains in order to determine the influence of the bioaugmentation on the mineralization of the MTZ electrolysis by-products. The use of acclimated bacteria for activated sludge bioaugmentation was more effective than the addition of non-acclimated bacteria (Fig.7). Indeed, for non-acclimated bacteria, the mineralization yields obtained were 56.7, 53.7, and $54.3 \%$ for the isolated strains A, B and the co-culture AB (50\%/50\%) respectively, whereas it increased to 80.1 (strain A), 85.2 (strain B), and $91.6 \%$ (co-culture $\mathrm{AB})$ for acclimated bacteria. In fact, the success of bioaugmentation is conditioned by the survival of inoculated bacteria in activated sludge; and the implementation of strains acclimated to the conditions of the culture can improve the resistance of the strains to survive and to be able to degrade the pollutants [48].

By comparing the results of Fig.7 with the results of Figs.5 and 6, it could be seen that the presence of the activated sludge had a positive influence on the mineralization of the electrolysis by-products. The presence of activated sludge increased the mineralization yields, since they were $80.1,85.2,91.6 \%$, while they were $75.6,72.9,65.9 \%$ in the absence of activated sludge, for the acclimated strains A, B and their co-culture AB (50\%/50\%) respectively. It can also be observed that the bioaugmentation with the co-culture A and $\mathrm{B}$ was the most efficient, with respect to bioaugmentation with strains A or B. Indeed, the use of the strains consortium as a bioaugmenting agent is advantageous owing to the diversity of the microorganisms metabolism [49]. Similarly, several studies have shown that using a microbial consortium in bioaugmentation can increase the rate of degradation of pollutants [50,51].

It could also be seen that the bioaugmentation of activated sludge by the two isolated strains improved the mineralization of the electrolysis by-products if compared to the use of activated sludge alone, $58.1 \%$ final mineralization yield (Fig. 4). This improvement of the performances may be related to synergistic phenomena between the microbial consortium present in the activated sludge and the inoculated strains [52] and/or by the formation in the 
culture medium of an extracellular degradation-enhancing metabolites or surfactants to improve the accessibility of refractory organic compounds to the microorganisms from activated sludge or isolated strains [53]. Several studies have reported the effectiveness of the bioaugmentation of activated sludge by specific strains to degrade pollutants; for example, degradation of 4-chlorophenol was successfully achieved by bioaugmenting activated sludge by Pseudomonas Putida [33], or the bioaugmentation of activated sludge with Advenella strains to degrade p-cresol [54].

\subsection{Effect of biostimulation}

The second technique of advanced biological process carried out in this study was the biostimulation. In fact, the addition of nutrients to activated sludge can change the dynamics of electrolysis by-product removal. For this reason, the biostimulation was applied by addition of glucose as a second carbon source in order to activate the growth of microorganisms. Fig. 8 shows the effect of the biostimulation of the activated sludge by glucose $\left(1 \mathrm{~g} . \mathrm{L}^{-1}\right)$ in order to mineralize the electrolysis by-products. The dissolved organic carbon (DOC) was composed of glucose and the electrolysis by-products. However, after $24 \mathrm{~h}$ the added glucose was totally consumed (Data not shown), and hence, the remaining DOC corresponded only to the electrolysis by-products. A positive impact of the biostimulation was observed, since the final mineralization yield (after $120 \mathrm{~h}$ ) increased from $58.1 \%$ to $81.5 \%$ in the absence and the presence of glucose respectively. The positive effect of biostimulation on pollutant degradation had been reported in various studies. Muter et $a l$. studied the biodegradation of 21 pharmaceutical compounds detected in wastewater using biostimulation [55]. They showed that the addition of nutrients stimulated the biodegradation of most pharmaceutical compounds (erythromycin, sulfamethoxazole, etc.) [55]. Different studies also showed the efficacy of using biostimulation as a post-treatment after oxidation with Fenton's reagents for the treatment of hydrocarbons [56, 57].

However, by comparing these results to those given in Fig. 7, it could also be noted the higher efficiency of bioaugmentation if compared to biostimulation, in agreement with the related literature. Indeed, the research of Hamdi et al showed that the effectiveness of bioremediation is based on the use of specific and selective microorganisms rather than nutrient loading [58]. Bento et al. also showed that the use of bioaugmentation to degrade diesel oil is more effective than biostimulation [59]. 


\subsection{Effect of the combination of biostimulation and bioaugmentation}

The third advanced biological process proposed in this study was the combination of the biostimulation and the bioaugmentation. This combination can lead to an increase of the microbial activity by adding substrate and specific microorganisms. In all experiments, the glucose was completely consumed after $24 \mathrm{~h}$ of treatment (Data not shown). The DOC which remained in the medium corresponded therefore to the electrolysis by-products. The effect of the combination was illustrated in Fig.8. It can be observed a positive impact of the combination of both processes, since biostimulation with glucose combined to bioaugmentation of activated sludge with an acclimated co-culture strains led to a mineralization yield of $96.1 \%$ of MTZ electrolysis by-products after $120 \mathrm{~h}$ of culture; slightly lower values were obtained in the case of biostimulation and activated sludge bioaugmentation with the acclimated isolated strain A or B, $88.8 \%$ and $85.3 \%$ respectively. These levels of mineralization were higher than those reached with biostimulation and slightly higher to those obtained for bioaugmentation (Figs.7 and 8). The difference in mineralization efficiency between bioaugmentation and coupled biostimulation/bioaugmentation should be related to the most recalcitrant organic compounds (hard COD), which accounted for the difficulty to further improved the process. Consequently, the coupling allowed to improve the mineralization of the hard COD and hence shows a higher treatment potential with respect to the bioaugmentation alone. Moreover and in favor of the integration of both strategies, various factors can limit the application of bioaugmentation, as for example the deficiency of substrate, while this latter ensures the proliferation and activation of microorganisms [60]. The combination of the two strategies improved the biodegradation of pollutants, since the nutrients provided by biostimulation were beneficial for activated sludge microorganisms on the one hand and A and B strains on the other hand. The efficiency of such combination has been reported by various authors, such as Silva et al. who observed that the rate of mineralization of atrazine was improved using Pseudomonas sp. Strain ADP as a bioaugmenting agent in the presence of citrate or succinate as a biostimulant [61].

We observed that the acclimation of the two isolated strains was overriding for autochthonous bioaugmentation, although the process requests several manipulations and time; a synergy between the two isolated strains most likely takes place. Pseudomonas putida (strain A) and Achromobacter sp (strain B), are certainly in the minority in activated sludge; the isolation and the acclimation allowed them to be predominant and more active for bioremediation of the electro-Fenton by-products. 


\subsection{Identification of by-products}

Based on the LC-MS/MS results, 5 by-products were detected after $60 \mathrm{~min}$ of electro-Fenton treatment (Table 2). These products were the result of the radical attacks from the Fenton reaction. These by-products constituted a part of the organic carbon available for the biological treatment. Detection of these by-products was carried out after $120 \mathrm{~h}$ of the biological treatment (Table 2); 3 of them were detected during activated sludge treatment, 2 in the case of biostimulation experiment, while only one during bioaugmentation (with the acclimated co-culture) and the combination of biostimulation and bioaugmentation experiments. Table 2 shows the demise of various electrolysis by-products after biological treatments and that only one remained after implementation of the most efficient ones, namely bioaugmentation and the biostimulation/bioaugmentation combination. 1-hydroxyethyl 2methyl 5-hydroxyimidazole from electro-Fenton treatment was not mineralized by the advanced biological treatment applied. It can therefore be assumed that the increase in mineralization was due to the degradation of these molecules. The degradation of the byproducts during the biological treatment was the result of their attack by the enzymes produced by the microorganisms in order to assimilate them as a source of carbon and/or energy; for example, hydrolases are involved in the cleavage of the C-C, C-O and C-N bonds and oxygenases in the cleavage of aromatic rings by introducing an $\mathrm{O}_{2}$ atom [62]. In the case of bioaugmentation and the combination of bioaugmentation and biostimulation, the results of by-products detection were similar; while, the mineralization yield in the case of the combination of bioaugmentation and biostimulation (Fig.8) was slightly higher than that of bioaugmentation (Fig.7). To account for that, it should be observed that during bioaugmentation some by-products were not degraded but biotransformed into other molecules, and the addition of glucose stimulates the growth of microorganisms that were capable of further biodegradation, which increased the rate of mineralization.

\section{Conclusion}

In previous work [30] we observed a total degradation of MTZ (100 $\left.\mathrm{mg} \mathrm{L}^{-1}\right)$ by electroFenton process at $0.07 \mathrm{~mA} . \mathrm{cm}^{-2}$ after only $20 \mathrm{~min}$ of electrolysis. However, after 1 and $2 \mathrm{~h}$ of electrolysis, the mineralization was only $16.2 \%$ and $32.0 \%$ respectively, signifying a 
significant residual organic content. Biological conventional treatment with activated sludge allowed to decrease the by-products of the MTZ electrolyse by only $58 \%$. In order to improve the biological treatment of MTZ by-products after electro-Fenton pretreatment, several strategies of biological treatment were carried out. Pure strains that were capable to mineralize the by-products of MTZ were isolated from activated sludge culture. The obtained results demonstrated that pure cultures of the isolated strains were less efficient than activated sludge. Various biological treatment strategies were then examined; the bioaugmentation of activated sludge by the isolated strain was more powerful than the biostimulation by addition of glucose. However, combining the two strategies, namely bio-augmentation of activated sludge with a co-culture of the two isolated strains, and biostimulation with glucose led to the most striking results. The mineralization of MTZ by-products reached a yield of $96.1 \%$ after $120 \mathrm{~h}$ of culture, namely an almost total elimination, $97 \%$ if both the pretreatment and the biological process were considered. By comparing these results with the conventional biological treatment of metronidazole discussed in a previous study [30], it is possible to conclude that coupling electro-Fenton pretreatment with advanced biological process to mineralize metronidazole is an effective process since it not only improves the overall mineralization yield $(+11.5 \%)$, but also drastically reduces the processing time, by 16 days. So, we can affirm that the combined treatment (electro-Fenton process with advanced biological process) is more efficient than electro-Fenton process alone for the removal of MTZ. The time saving should be helpful in view of future implementation at large scale, since it should allow to reduce residence time and tank volumes.

\section{References}

[1] E. Ngumba, P. Kosunen, A. Gachanja, T. Tuhkanen, A multiresidue analytical method for trace level determination of antibiotics and antiretroviral drugs in wastewater and surface water using SPE-LC-MS/MS and matrix-matched standards, Anal. Methods. 8 (2016) 6720-6729. https://doi.org/10.1039/C6AY01695B.

[2] M.T. Meyer, J.E. Bumgarner, J.V. Daughtridge, D. Kolpin, E.M. Thurman, K.A. Hostetler, Occurrence of antibiotics in liquid waste at confined animal feeding operations and in surface and ground water, in: US Geological Survey, Raleigh, NC Abstract Presented at Animal Feeding Operations: Effects on Hydrologic Resources and the Environment Workshop, Aug, 1999.

[3] K. Kümmerer, A. Al-Ahmad, V. Mersch-Sundermann, Biodegradability of some antibiotics, elimination of the genotoxicity and affection of wastewater bacteria in a simple test, Chemosphere. 40 (2000) 701-710.

[4] L. Migliore, C. Civitareale, G. Brambilla, G.D. Di Delupis, Toxicity of several important agricultural antibiotics to Artemia, Water Research. 31 (1997) 1801-1806. 
[5] P.F. Lanzky, B. Halting-Sørensen, The toxic effect of the antibiotic metronidazole on aquatic organisms, Chemosphere. 35 (1997) 2553-2561.

[6] G. Le Page, L. Gunnarsson, J. Snape, C.R. Tyler, Integrating human and environmental health in antibiotic risk assessment: A critical analysis of protection goals, species sensitivity and antimicrobial resistance, Environment International. 109 (2017) 155-169. https://doi.org/10.1016/j.envint.2017.09.013.

[7] A. Kumar, S. Kumar Sharna, G. Sharna, C. Guo, D.-V.N. Vo, J. Iqbal, M. Naushad, F.J. Stadler, Silicate glass matrix $@ \mathrm{Cu}_{2} \mathrm{O} / \mathrm{Cu}_{2} \mathrm{~V}_{2} \mathrm{O}_{7}$ p-n heterojunction for enhanced visible light photo-degradation of sulfamethoxazole: High charge separation and interfacial transfer, Journal of Hazardous Materials. 402 (2021) 123790.

[8] T. Ahamad, M. Naushad, Y. Alzaharani, S.M. Alshehri, Photocatalytic degradation of bisphenol-A with $\mathrm{g}-\mathrm{C}_{3} \mathrm{~N}_{4} / \mathrm{MoS}_{2}$-PANI nanocomposite: kinetics, main active species, intermediates, Journal of Molecular Liquids. 311 (2020) 113339.

[9] A.J. dos Santos, M.S. Kronka, G.V. Fortunato, M.R.V. Lanza, Recent advances in electrochemical water technologies for the treatment of antibiotics: A short review, Current Opinion in Electrochemistry. 26 (2021) 100674.

[10] A. Abou Dalle, L. Domergue, F. Fourcade, A.A. Assadi, H. Djelal, T. Lendormi, I. Soutrel, S. Taha, A. Amrane, Efficiency of DMSO as hydroxyl radical probe in an Electrochemical Advanced Oxidation Process_Reactive oxygen species monitoring and impact of the current density, Electrochimica Acta. 246 (2017) 1-8.

[11] F. Ferrag-Siagh, F. Fourcade, I. Soutrel, H. Aït-Amar, H. Djelal, A. Amrane, ElectroFenton pretreatment for the improvement of tylosin biodegradability, Environ Sci Pollut Res. 21 (2014) 8534-8542. https://doi.org/10.1007/s11356-014-2771-5.

[12] O. Ganzenko, C. Trellu, N. Oturan, D. Huguenot, Y. Péchaud, E.D. van Hullebusch, M.A. Oturan, Electro-Fenton treatment of a complex pharmaceutical mixture: Mineralization efficiency and biodegradability enhancement, Chemosphere. 253 (2020) 126659. https://doi.org/10.1016/j.chemosphere.2020.126659.

[13] H. Olvera-Vargas, N. Gore-Datar, O. Garcia-Rodriguez, S. Mutnuri, O. Lefebvre, Electro-Fenton treatment of real pharmaceutical wastewater paired with a BDD anode: Reaction mechanisms and respective contribution of homogeneous and heterogeneous OH, Chemical Engineering Journal. 404 (2021) 126524.

[14] A. Kumar, G. Sharma, M. Naushad, A.H. Al-Muhtaseb, A. Garcia-Penas, G.T. Mola, C. Si, F.J. Stadler, Bio-inspired and biomaterials-based hybrid photocatalysts for environmental detoxification: A review, Chemical. Engineering Journal 382 (2020) 122937.

[15] S. Semrany, L. Favier, H. Djelal, S. Taha, A. Amrane, Bioaugmentation: possible solution in the treatment of bio-refractory organic compounds (Bio-ROCs), Biochemical Engineering Journal. 69 (2012) 75-86.

[16] H. Djelal, P. Estrada Martinez, D. Haddouche, M. Chabani, Assessment of the biodegradation of doxycycline by biostimulation with addition of glucose, phenol or/and copper, Ecocycles. (2020) 6 (2) 25-31.

[17] J. Li, K. Peng, D. Zhang, C. Luo, X. Cai, Y. Wang, G. Zhang, Autochthonous bioaugmentation with non-direct degraders: A new strategy to enhance wastewater bioremediation performance, Environment International. 136 (2020) 105473.

[18] I. Saidi, I. Soutrel, D. Floner, F. Fourcade, N. Bellakhal, A. Amrane, F. Geneste, Indirect electroreduction as pretreatment to enhance biodegradability of metronidazole, Journal $\begin{array}{lllll}\text { of Hazardous } & \text { Materials. } & 278 & \text { (2014) }\end{array}$ https://doi.org/10.1016/j.jhazmat.2014.06.003. 
[19] H. Shemer, Y.K. Kunukcu, K.G. Linden, Degradation of the pharmaceutical metronidazole via UV, Fenton and photo-Fenton processes, Chemosphere. 63 (2006) 269-276.

[20] V. Sarria, M. Deront, P. Péringer, C. Pulgarin, Degradation of a biorecalcitrant dye precursor present in industrial wastewaters by a new integrated iron (III) photoassistedbiological treatment, Applied Catalysis B: Environmental. 40 (2003) 231-246.

[21] C. Pulgarin, M. Invernizzi, S. Parra, V. Sarria, R. Polania, P. Péringer, Strategy for the coupling of photochemical and biological flow reactors useful in mineralization of biorecalcitrant industrial pollutants, Catalysis Today. 54 (1999) 341-352.

[22] S. Parra, V. Sarria, S. Malato, P. Péringer, C. Pulgarin, Photochemical versus coupled photochemical-biological flow system for the treatment of two biorecalcitrant herbicides: metobromuron and isoproturon, Applied Catalysis B: Environmental. 27 (2000) 153-168.

[23] H. Monteil, Y. Péchaud, N. Oturan, M.A. Oturan, A review on efficiency and cost effectiveness of electro- and bio-electro-Fenton processes: Application to the treatment of pharmaceutical pollutants in water, Chemical Engineering Journal. 376 (2019) 119577. https://doi.org/10.1016/j.cej.2018.07.179.

[24] C. Annabi, F. Fourcade, I. Soutrel, F. Geneste, D. Floner, N. Bellakhal, A. Amrane, Degradation of enoxacin antibiotic by the electro-Fenton process: Optimization, biodegradability improvement and degradation mechanism, Journal of Environmental Management. 165 (2016) 96-105.

[25] D. Mansour, F. Fourcade, N. Bellakhal, M. Dachraoui, D. Hauchard, A. Amrane, Biodegradability improvement of sulfamethazine solutions by means of an electroFenton process, Water, Air, \& Soil Pollution. 223 (2012) 2023-2034.

[26] M. Alexander, Biodegradation and bioremediation, Gulf Professional Publishing, 1999.

[27] T. Gentry, C. Rensing, I.A.N. Pepper, New approaches for bioaugmentation as a remediation technology, Critical Reviews in Environmental Science and Technology. 34 (2004) 447-494.

[28] M. Cycoń, A. Mrozik, Z. Piotrowska-Seget, Bioaugmentation as a strategy for the remediation of pesticide-polluted soil: A review, Chemosphere. 172 (2017) 52-71. https://doi.org/10.1016/j.chemosphere.2016.12.129.

[29] E.E. Raimondo, J.M. Saez, J.D. Aparicio, M.S. Fuentes, C.S. Benimeli, Coupling of bioaugmentation and biostimulation to improve lindane removal from different soil types, Chemosphere. $\quad 238 \quad$ (2020) https://doi.org/10.1016/j.chemosphere.2019.124512.

124512.

[30] A. Aboudalle, H. Djelal, F. Fourcade, L. Domergue, A.A. Assadi, T. Lendormi, S. Taha, A. Amrane, Metronidazole removal by means of a combined system coupling an electroFenton process and a conventional biological treatment: By-products monitoring and performance enhancement, Journal of Hazardous Materials. 359 (2018) 85-95. https://doi.org/10.1016/j.jhazmat.2018.07.006.

[31] N.A. Salles, F. Fourcade, F. Geneste, D. Floner, A. Amrane, Relevance of an electrochemical process prior to a biological treatment for the removal of an organophosphorous pesticide, phosmet, Journal of Hazardous Materials. 181 (2010) 617-623. https://doi.org/10.1016/j.jhazmat.2010.05.057.

[32] K.-C. Loh, B. Cao, Paradigm in biodegradation using Pseudomonas putida-a review of proteomics studies, Enzyme and Microbial Technology. 43 (2008) 1-12.

[33] H. McLaughlin, A. Farrell, B. Quilty, Bioaugmentation of activated sludge with two Pseudomonas putida strains for the degradation of 4-chlorophenol, Journal of Environmental Science and Health Part A. 41 (2006) 763-777. 
[34] S. Selvaratnam, B.A. Schoedel, B.L. McFarland, C.F. Kulpa, Application of the polymerase chain reaction (PCR) and reverse transcriptase/PCR for determining the fate of phenol-degrading Pseudomonas putida ATCC 11172 in a bioaugmented sequencing batch reactor, Applied Microbiology and Biotechnology. 47 (1997) 236-240.

[35] Y.V. Nancharaiah, H.M. Joshi, M. Hausner, V.P. Venugopalan, Bioaugmentation of aerobic microbial granules with Pseudomonas putida carrying TOL plasmid, Chemosphere. 71 (2008) 30-35.

[36] P.Y. Nguyen, G. Carvalho, A.C. Reis, O.C. Nunes, M.A.M. Reis, A. Oehmen, Impact of biogenic substrates on sulfamethoxazole biodegradation kinetics by Achromobacter denitrificans strain PR1, Biodegradation. 28 (2017) 205-217.

[37] M. Huang, S. Tian, D. Chen, W. Zhang, J. Wu, L. Chen, Removal of sulfamethazine antibiotics by aerobic sludge and an isolated Achromobacter sp. S-3, Journal of Environmental Sciences. 24 (2012) 1594-1599.

[38] P.J. Reis, A.C. Reis, B. Ricken, B.A. Kolvenbach, C.M. Manaia, P.F. Corvini, O.C. Nunes, Biodegradation of sulfamethoxazole and other sulfonamides by Achromobacter denitrificans PR1, Journal of Hazardous Materials. 280 (2014) 741-749.

[39] C. Zhang, G. Zeng, L. Yuan, J. Yu, J. Li, G. Huang, B. Xi, H. Liu, Aerobic degradation of bisphenol A by Achromobacter xylosoxidans strain B-16 isolated from compost leachate of municipal solid waste, Chemosphere. 68 (2007) 181-190.

[40] A. Mrozik, Z. Piotrowska-Seget, Bioaugmentation as a strategy for cleaning up of soils contaminated with aromatic compounds, Microbiological Research. 165 (2010) 363375.

[41] G. Buitrón, A. González, L.M. López-Marín, Biodegradation of phenolic compounds by an acclimated activated sludge and isolated bacteria, Water Science and Technology. 37 (1998) 371-378.

[42] C. Derradji, Traitement des eaux usées industrielles : Dégradation des colorants azoïques par un procédé intégré couplant un procédé d'oxydation avancée et un traitement biologique, 2012.

[43] C.-J. Lu, C.-M. Lee, M.-S. Chuang, Effects of acclimation on the biodegradation of 2Chlorophenol in an immobilized-cell reactor, Journal of the Chinese Institute of Environmental Engineering. 5 (1995).

[44] E. Kaczorek, K. Sallek, U. Guzik, B. Dudzińska-Bajorek, A. Olszanowski, The impact of long-term contact of Achromobacter sp. 4 (2010) with diesel oil-changes in biodegradation, surface properties and hexadecane monooxygenase activity, International Biodeterioration \& Biodegradation. 78 (2013) 7-16.

[45] O.A. Ojo, Molecular strategies of microbia adaptation to xenobiotics in natural environment, Biotechnology and Molecular Biology Reviews. 2 (2007) 1-13.

[46] A. Pacholak, W. Smułek, T. Jesionowski, E. Kaczorek, The ability of Achromobacter sp. KW1 strain to biodegrade isomers of chlorotoluene, J. Chem. Technol. Biotechnol. (2017) 2134-2141. https://doi.org/10.1002/jctb.5221.

[47] S. Takenaka, T. Tonoki, K. Taira, S. Murakami, K. Aoki, Adaptation of Pseudomonas sp. Strain 7-6 to Quaternary Ammonium Compounds and Their Degradation via Dual Pathways, Appl. Environ. Microbiol. 73 (2007) 1797-1802. https://doi.org/10.1128/AEM.02426-06.

[48] H.V. Limbergen, E.M. Top, W. Verstraete, Bioaugmentation in activated sludge: current features and future perspectives, Applied Microbiology and Biotechnology. 50 (1998) $16-23$.

[49] M. Tyagi, M.M.R. da Fonseca, C.C.C.R. de Carvalho, Bioaugmentation and biostimulation strategies to improve the effectiveness of bioremediation processes, Biodegradation. 22 (2011) 231-241. https://doi.org/10.1007/s10532-010-9394-4. 
[50] X. Li, X. Lin, P. Li, W. Liu, L. Wang, F. Ma, K.S. Chukwuka, Biodegradation of the low concentration of polycyclic aromatic hydrocarbons in soil by microbial consortium during incubation, Journal of Hazardous Materials. 172 (2009) 601-605. https://doi.org/10.1016/j.jhazmat.2009.07.044.

[51] C. Alisi, R. Musella, F. Tasso, C. Ubaldi, S. Manzo, C. Cremisini, A.R. Sprocati, Bioremediation of diesel oil in a co-contaminated soil by bioaugmentation with a microbial formula tailored with native strains selected for heavy metals resistance, Science of The Total Environment. $407 \quad$ (2009) 3024-3032. https://doi.org/10.1016/j.scitotenv.2009.01.011.

[52] E. Heinaru, M. Merimaa, S. Viggor, M. Lehiste, I. Leito, J. Truu, A. Heinaru, Biodegradation efficiency of functionally important populations selected for bioaugmentation in phenol-and oil-polluted area, FEMS Microbiology Ecology. 51 (2005) 363-373.

[53] Y. Yao, Z. Lu, F. Zhu, H. Min, C. Bian, Successful bioaugmentation of an activated sludge reactor with Rhodococcus sp. YYL for efficient tetrahydrofuran degradation, Journal of Hazardous Materials. 261 (2013) 550-558.

[54] E. Xenofontos, A.-M. Tanase, I. Stoica, I. Vyrides, Newly isolated alkalophilic Advenella species bioaugmented in activated sludge for high p-cresol removal, New Biotechnology. 33 (2016) 305-310. https://doi.org/10.1016/j.nbt.2015.11.003.

[55] O. Muter, I. Plerkons, T. Selga, A. Berzins, D. Gudra, I. Radovica-Spalvina, D. Fridmanis, V. Bartkevics, Removal of pharmaceuticals from municipal wastewaters at laboratory scale by treatment with activated sludge and biostimulation, Science of The Total Environment. $\quad 584-585 \quad$ (2017) 402-413. https://doi.org/10.1016/j.scitotenv.2017.01.023.

[56] C. Calvo, G.A. Silva-Castro, I. Uad, M. Manzanera, C. Perucha, J. Laguna, J. GónzalezLópez, Biostimulation combined treatments for remediation of diesel contaminated soil, WIT Transactions on Ecology and the Environment. 132 (2010) 111-119.

[57] G.A. Silva-Castro, B. Rodelas, C. Perucha, J. Laguna, J. González-López, C. Calvo, Bioremediation of diesel-polluted soil using biostimulation as post-treatment after oxidation with Fenton-like reagents: assays in a pilot plant, Science of the Total Environment. 445 (2013) 347-355.

[58] H. Hamdi, S. Benzarti, L. Manusadžianas, I. Aoyama, N. Jedidi, Bioaugmentation and biostimulation effects on PAH dissipation and soil ecotoxicity under controlled conditions, Soil Biology and Biochemistry. 39 (2007) 1926-1935.

[59] F.M. Bento, F.A. Camargo, B.C. Okeke, W.T. Frankenberger, Comparative bioremediation of soils contaminated with diesel oil by natural attenuation, biostimulation and bioaugmentation, Bioresource Technology. 96 (2005) 1049-1055.

[60] T. Bouchez, D. Patureau, P. Dabert, S. Juretschko, J. Dore, P. Delgenes, R. Moletta, M. Wagner, Ecological study of a bioaugmentation failure, Environmental Microbiology. 2 (2000) 179-190.

[61] E. Silva, A.M. Fialho, I. Sá-Correia, R.G. Burns, L.J. Shaw, Combined Bioaugmentation and Biostimulation To Cleanup Soil Contaminated with High Concentrations of Atrazine, Environ. Sci. Technol. 38 (2004) 632-637. https://doi.org/10.1021/es0300822.

[62] C.S. Karigar, S.S. Rao, Role of microbial enzymes in the bioremediation of pollutants: a review, Enzyme Research. 2011 (2011). 


\section{Figure captions}

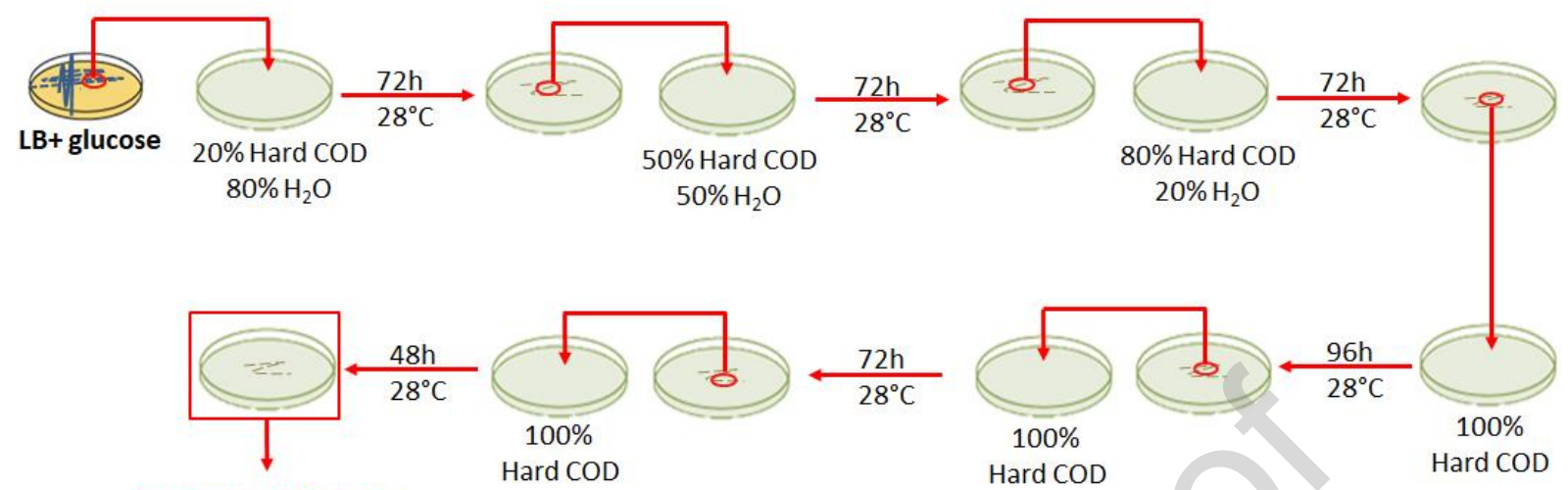

Figure 1

Figure 1: Experimental protocol for the acclimatization of isolated strains (LB: Luria-Bertani medium)

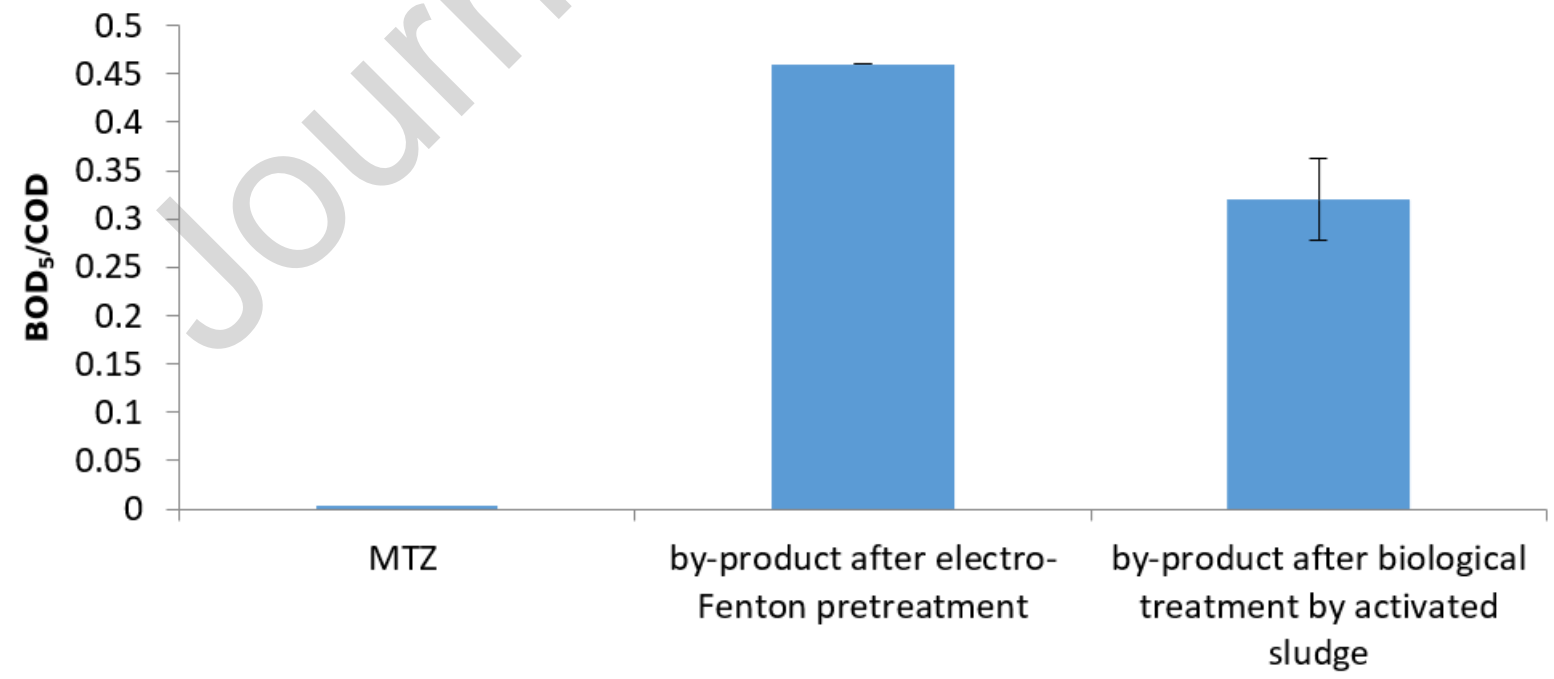

Figure 2 
Figure 2: The biodegradability of MTZ (100 mg. $\left.\mathrm{L}^{-1}\right)$ and its by-products after electro-Fenton pretreatment at $100 \mathrm{~mA}, \mathrm{pH} 3,\left[\mathrm{Na}_{2} \mathrm{SO}_{4}\right]=50 \mathrm{mmol} \cdot \mathrm{L}^{-1}$ and $\left[\mathrm{Fe}^{2+}\right]=0.1 \mathrm{mmol} \cdot \mathrm{L}^{-1}$ and after 4 days of biological treatment using 0.5 g. $\mathrm{L}^{-1}$ of activated sludge, $\mathrm{pH}=7$ and nutriments

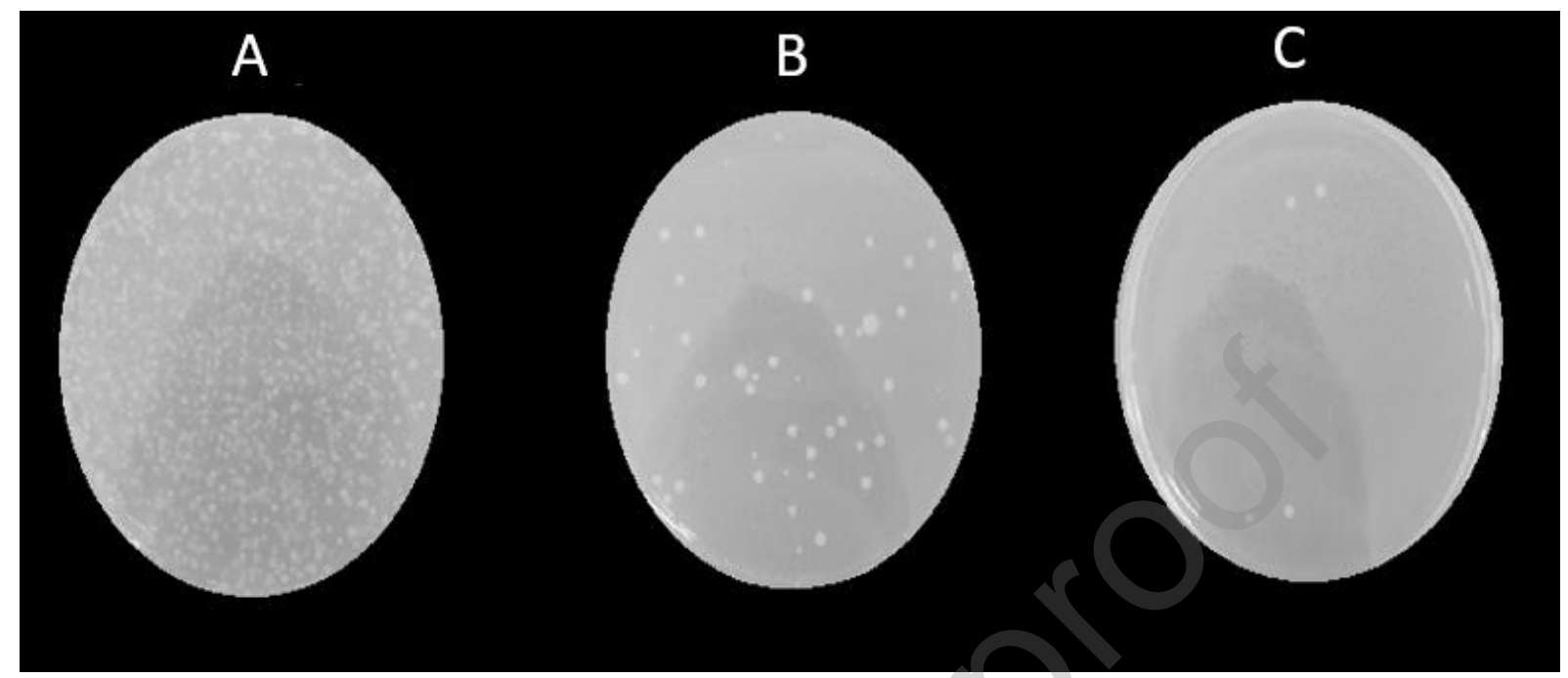

Figure 3 
Figure 3: Culture of activated sludge at $25^{\circ} \mathrm{C}$ on Petri dishes after biological treatment of the electrolysis by-product: A : after 1 day of biological treatment, dilution $10^{-2}$, incubation $24 \mathrm{~h}$; B : after 4 days of biological treatment, dilution $10^{-2}$, incubation $24 \mathrm{~h}$; and $\mathrm{C}$ after 21 days of treatment, dilution $10^{-1}$, incubation $72 \mathrm{~h}$

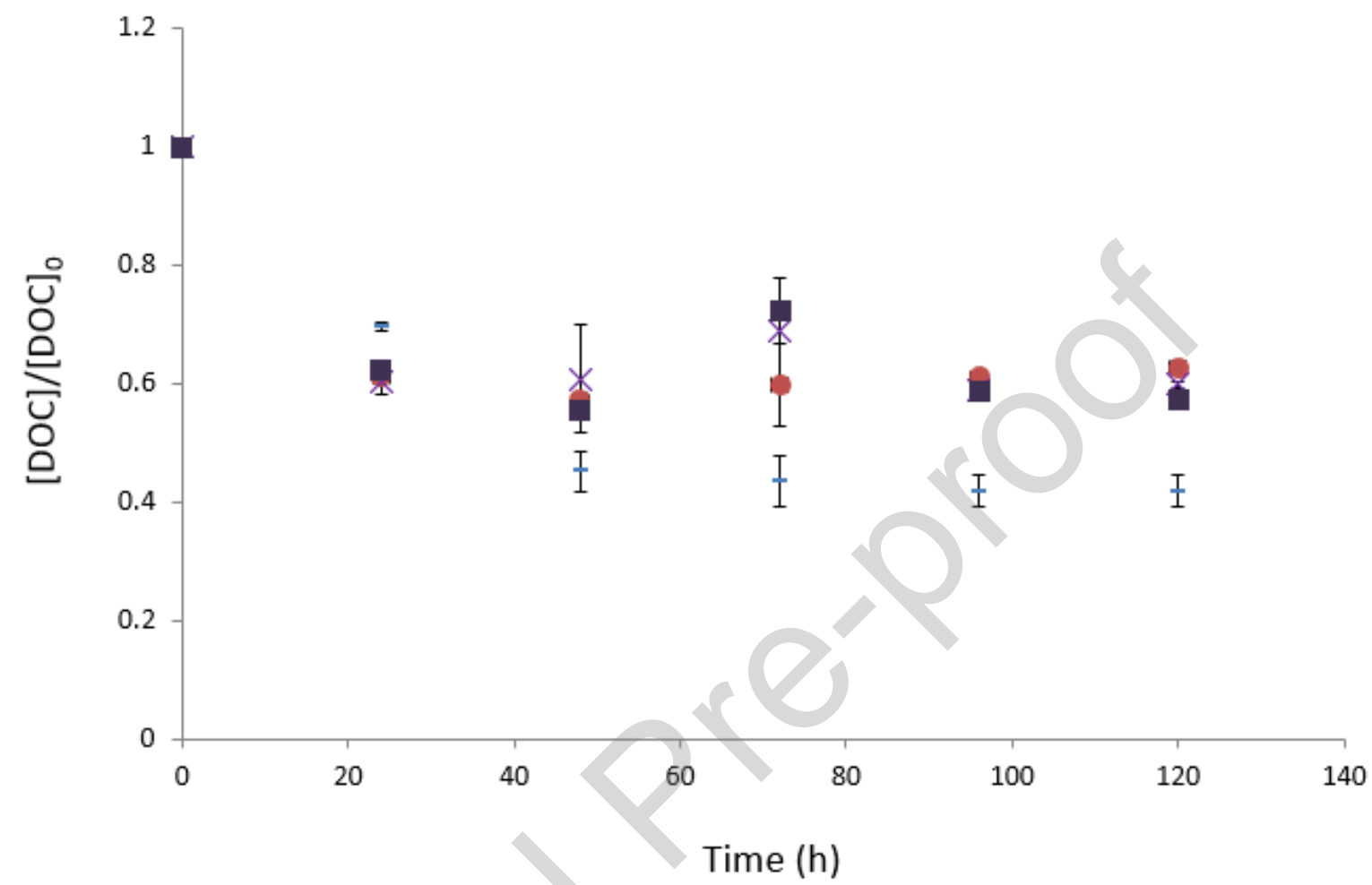

Figure 4: Time courses of the mineralization of MTZ electrolyzed solutions by activated sludge 0.5 g.L $\mathrm{L}^{-1}(-)$, strain A $4 \% \mathrm{v} / \mathrm{v}(\bullet)$, strain B $4 \%$ (v/v) (x), co-culture $50 \%$ \% 0 \% ( ) 


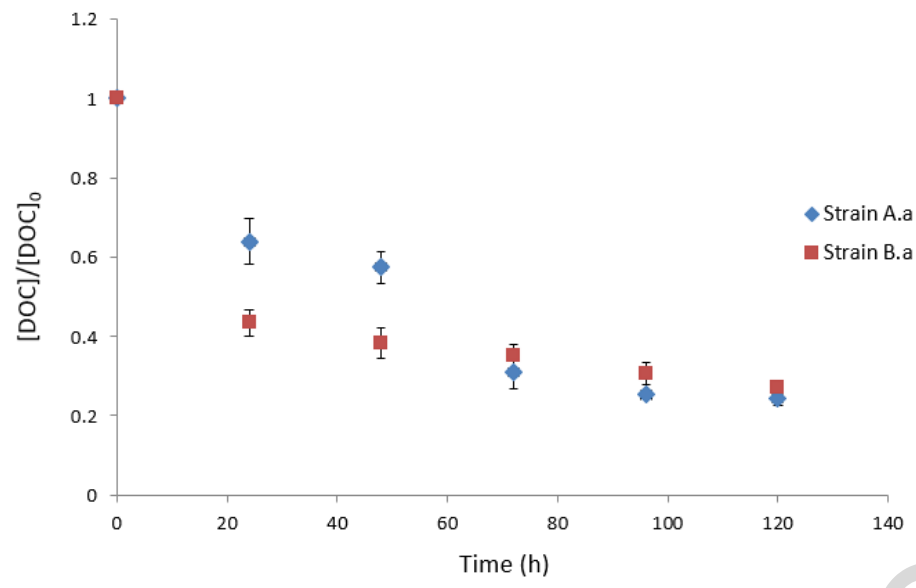

Figure 5

Figure 5: The effect of acclimation on the mineralization of by-products. $(a)=$ acclimated. Experimental conditions: inoculums volume: $4 \% \mathrm{v} / \mathrm{v}, \mathrm{pH}=7,28^{\circ} \mathrm{C}, 150 \mathrm{rpm}$.

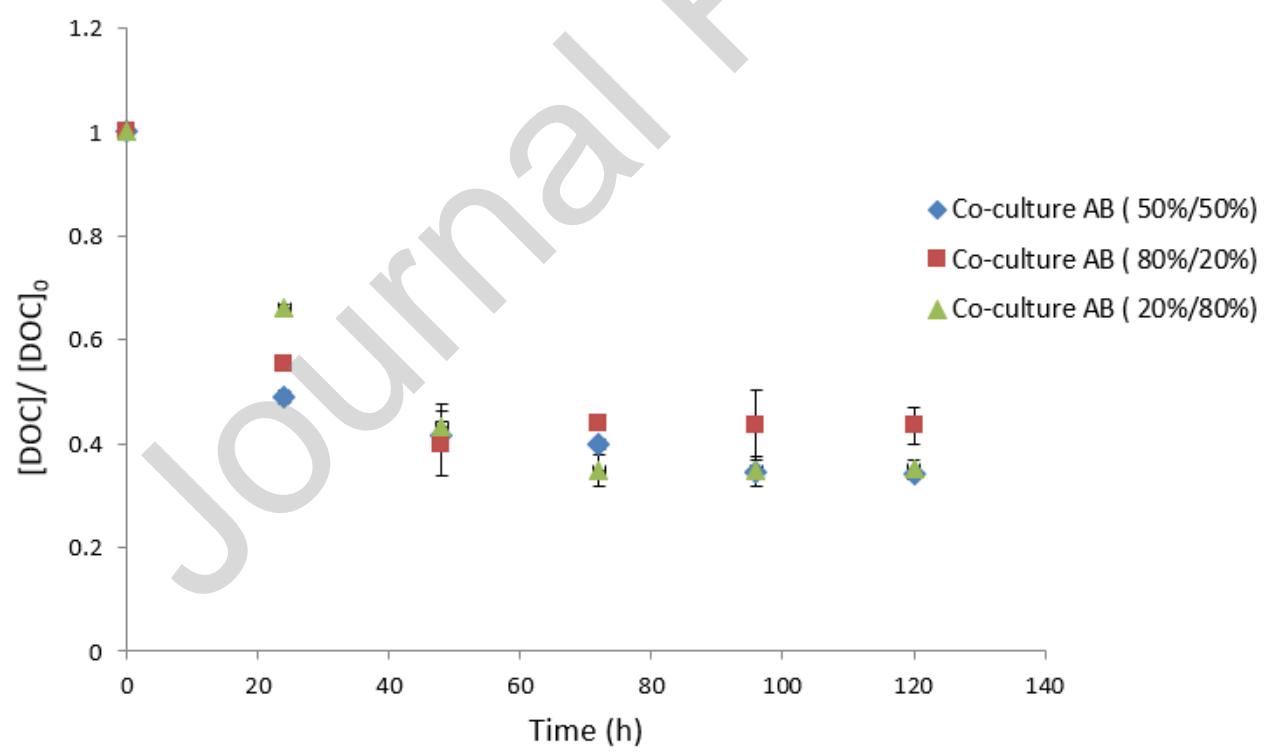

Figure 6

Figure 6: Comparison of DOC values during the co-culture with different ratios. The total volume of inoculum was $4 \%(\mathrm{v} / \mathrm{v})$ 


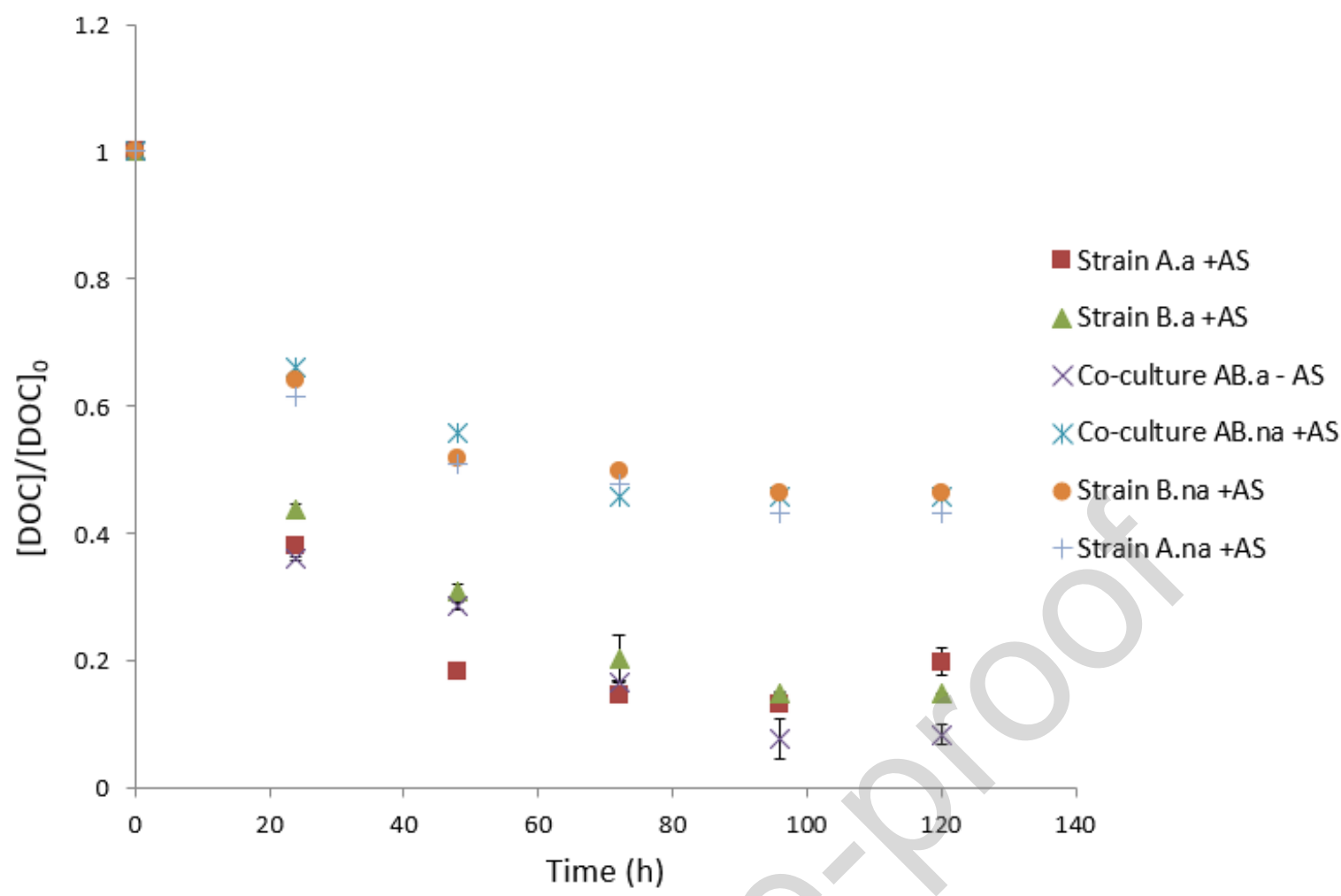

Figure 7

Figure 7: The effect of the bioaugmentation on the mineralization of electrolysis by-products. $(\mathrm{a})=$ acclimated, $(\mathrm{na})=$ non-acclimated, $(\mathrm{AS})=$ Activated sludge. Co-culture $\mathrm{AB}=$ $50 \%$ A $/ 50 \%$ B. Conditions: $[\mathrm{AS}]=0.5 \mathrm{~g} \cdot \mathrm{L}^{-1},[\mathrm{glu}]=1 \mathrm{~g} . \mathrm{L}^{-1}$, inoculation volume $=4 \% \mathrm{v} / \mathrm{v}$, $\mathrm{pH}=7,28^{\circ} \mathrm{C}, 150 \mathrm{rpm}$ 
co-culture AB.a+AS+glu

Strain B.a+AS+glu strain A.a+AS+glu co-culture AB.a+AS

strain B.a+AS strain A.a+AS

AS+glu

AS
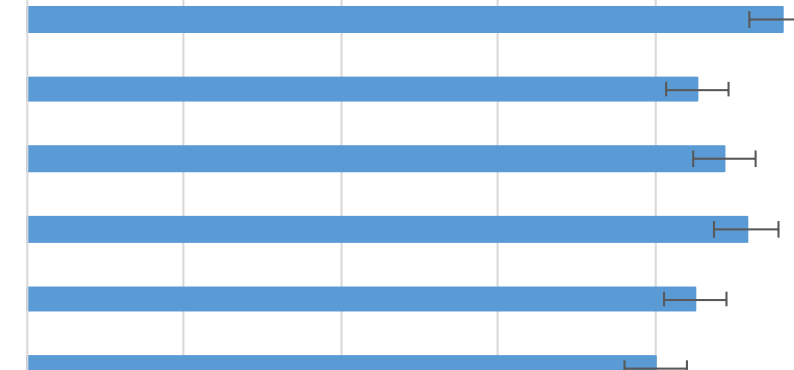

AS 0

20

40

60

80

100

Figure 8

Figure 8: The effect of the biostimulation, bioaugmentation and the combination of bioaugmentation and biostimulation on the mineralization yield after $120 \mathrm{~h}$ of treatment. $(\mathrm{a})=$ acclimated, $(\mathrm{AS})=$ Activated sludge. Co-culture $\mathrm{AB}=50 \% \mathrm{~A} / 50 \%$ B. Conditions: $[\mathrm{glu}]=$ $1 \mathrm{~g} . \mathrm{L}^{-1},[\mathrm{AS}]=0.5 \mathrm{~g} . \mathrm{L}^{-1}$, inoculation volume $=4 \% \mathrm{v} / \mathrm{v}, \mathrm{pH}=7,28^{\circ} \mathrm{C}, 150 \mathrm{rpm}$ 
Table 1: The experimental conditions for biological treatment

\begin{tabular}{ccccc} 
Biological treatment & $\begin{array}{c}\text { Activate } \\
\text { sludge } \\
\left(\mathbf{0 . 5} \text { g. } \mathbf{L}^{-1}\right)\end{array}$ & $\begin{array}{c}\text { Strain(s) } \\
\text { isolated }\end{array}$ & $\begin{array}{c}\text { Organic } \\
\text { Nutrient }\end{array}$ & $\begin{array}{c}\text { Inorganic } \\
\text { Nutrients }\end{array}$ \\
Activated sludge & + & - & - & + \\
\hline Pure culture & - & + & + & + \\
\hline Biostimulation & + & - & + & + \\
\hline Bioaugmentation & + & + & - & + \\
\hline $\begin{array}{c}\text { Combination of } \\
\text { biostimulation / } \\
\text { bioaugmentation }\end{array}$ & + & + & + & + \\
\hline
\end{tabular}

Presence : (+)

Absence : (-)

Organic Nutrient $\left(\mathrm{g} . \mathrm{L}^{-1}\right)$ glucose : 1

Inorganic Nutrients (mg. $\mathrm{L}^{-1}$ ) : $\mathrm{K}_{2} \mathrm{HPO}_{4}$ (208); $\mathrm{KH}_{2} \mathrm{PO}_{4},(85) ; \mathrm{Na}_{2} \mathrm{HPO}_{4}, 2 \mathrm{H}_{2} \mathrm{O}$ (154.4); $\mathrm{MgSO}_{4}, 7 \mathrm{H}_{2} \mathrm{O}$ (22.6); $\mathrm{CaCl}_{2}$ (27.6); $\mathrm{FeCl}_{3}, 6 \mathrm{H}_{2} \mathrm{O}(0.26) ; \mathrm{NH}_{4} \mathrm{Cl}$ (75). 
Table 2: The identification of electrolysis by-product during the different biological treatments

\begin{tabular}{|c|c|c|c|c|c|}
\hline Name & $\begin{array}{c}\text { 1-carboxyethyl } \\
2,5 \\
\text { dihydroxyimidaz } \\
\text { ole }\end{array}$ & $\begin{array}{c}2,5 \\
\text { dihydro } \\
\text { xy } \\
\text { imidazol } \\
\text { e }\end{array}$ & $\begin{array}{c}2,3,5- \\
\text { trihydroxyimidaz } \\
\text { ole }\end{array}$ & $\begin{array}{l}\text { 2hydrox } \\
\text { y 5- } \\
\text { methyl } \\
\text { imidazo } \\
\text { le }\end{array}$ & $\begin{array}{l}\text { 1-hydroxyethyl } \\
\text { 2-methyl 5- } \\
\text { hydroxyimidaz } \\
\text { ole }\end{array}$ \\
\hline $\begin{array}{l}\text { Chemical } \\
\text { structure }\end{array}$ & & & & & \\
\hline $\begin{array}{l}\text { Molar mass } \\
\left(\text { g.mol }^{-1}\right)\end{array}$ & 158 & 100 & 116 & 98 & 142 \\
\hline $\begin{array}{l}\text { Activated } \\
\text { sludge }\end{array}$ & + & - & & + & + \\
\hline Biostimulation & + & & - & - & + \\
\hline $\begin{array}{l}\text { Bioaugmentati } \\
\text { on with } \\
\text { acclimated co- } \\
\text { culture }\end{array}$ & _ & & - & - & + \\
\hline $\begin{array}{l}\text { Combination } \\
\text { of } \\
\text { bioaugmentati } \\
\text { on and } \\
\text { biostimulation }\end{array}$ & & - & - & - & + \\
\hline
\end{tabular}

$(+)=$ presence

$(-)=$ absence 


\section{Graphical abstract}

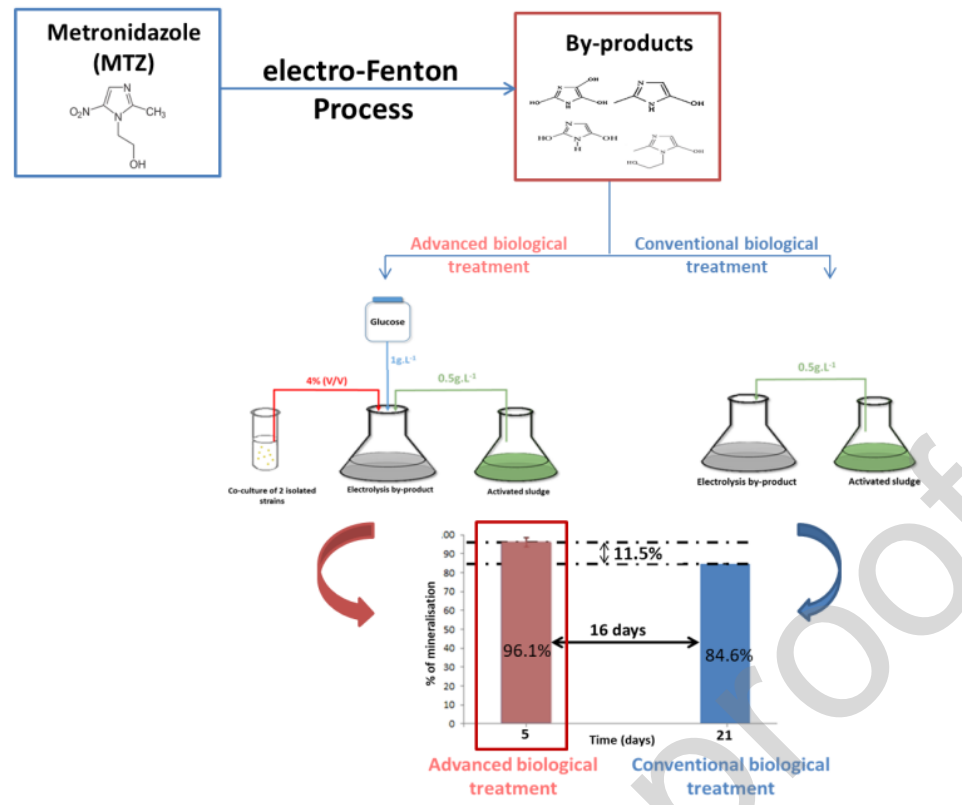


CRediT authorship contribution statement

Arwa ABOU DALLE: Conceptualization; Data curation; Formal analysis; Investigation; Visualization; Writing - original draft;

Hayet DJELAL: Conceptualization; Formal analysis; Funding acquisition; Project administration; Resources; Supervision; Validation; Visualization; Writing - review \& editing;

Lionel DOMERGUE: Formal analysis; Investigation; Writing;

Florence FOURCADE: Conceptualization; Funding acquisition; Resources; Supervision; Validation; Writing - review \& editing.

Abdeltif AMRANE: Conceptualization; Funding acquisition; Project administration; Resources; Supervision; Review \& editing. 


\section{Declaration of interests}

$\bigotimes$ The authors declare that they have no known competing financial interests or personal relationships that could have appeared to influence the work reported in this paper.

$\square$ The authors declare the following financial interests/personal relationships which may be considered as potential competing interests: 
Highlights

- Advanced biological treatments were proposed to improve mineralization of metronidazole by-products.

- Two strains were isolated during activated sludge culture of metronidazole byproducts, Pseudomonas putida and Achromobacter $s p$

- Bioaugmentation with each of these two strains and their co-culture was considered.

- Biostimulation, Bioaugmentation and their combination enhanced mineralization yields, $81.5 \%, 85.0 \%$ and $96.1 \%$ in $120 \mathrm{~h}$.

- Electro-Fenton coupled to advanced biological process led to $97 \%$ mineralization and drastic decrease of culture time. 